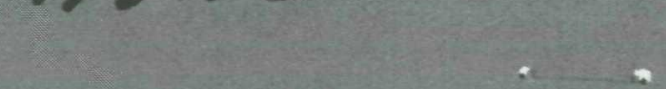

Fluid Mechanics Laboratory Publication No. 71.12

\title{
SOOT OXIDATION RATES IN GAS TURBINE ENGINES
}

Samuel W. Radcliffe and John P. Appleton

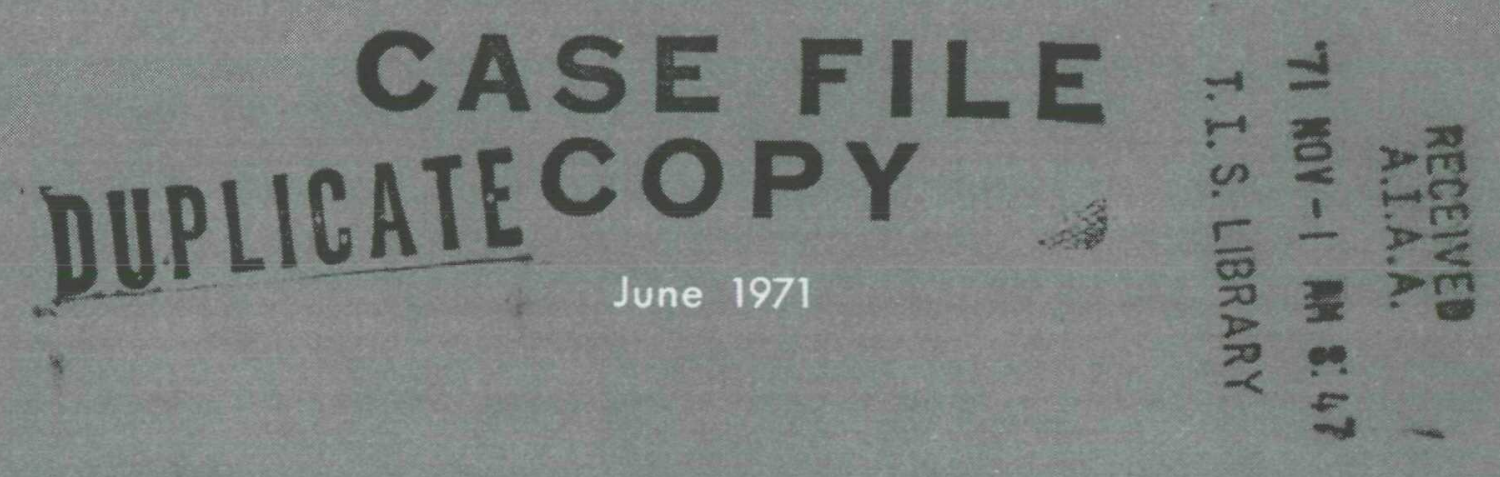

\section{FLUID MECHANICS LABORATORY}
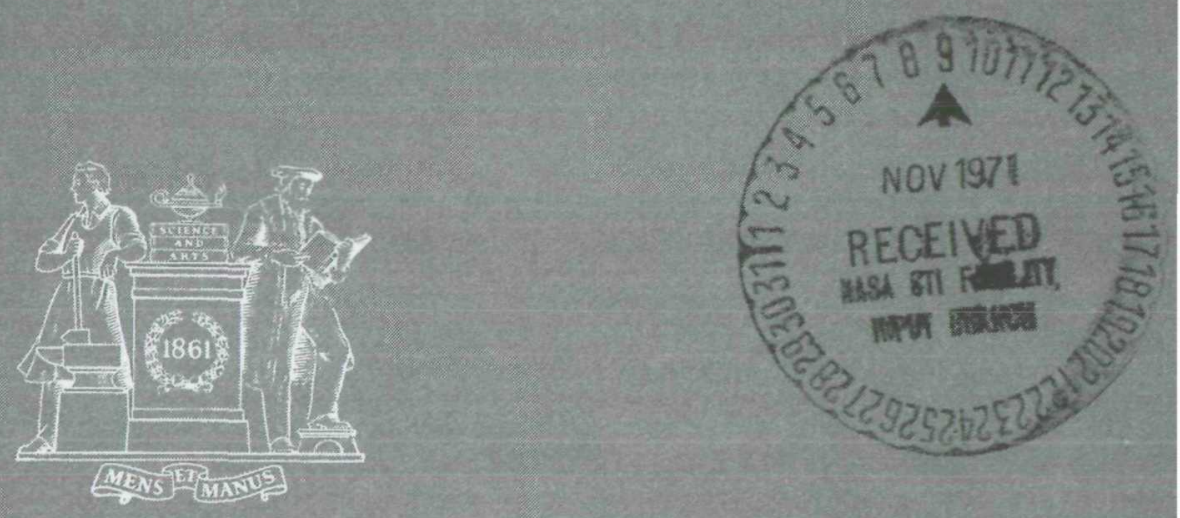

DEPARTMENT OF MECHANICAL ENGINEERING MASSACHUSETTS INSTITUTE OF TECHNOLOGY 
SOOT OXIDATION RATES IN GAS TURBINE ENGINES

by

Samuel W. Radcliffe and John P. Appleton

Fluid Mechanics Laboratory

Department of Hechanical Engineering

Massachusetts Institute of Technology

This work was supported by NASA Grant INGL 22-009-378

This document has been approved for public release and sale; its distribution is unlimited.

June 1971 


\title{
Soot Oxidation Rates in Gas Turbine Engines
}

$$
\text { by }
$$

Samuel W. Radcliffe and John P. Appleton

Massachusetts Institute of Technology, Cambridge, Massachusetts

\begin{abstract}
A basis for extrapolating soot oxidation rate measurements obtained in laboratory flames to the more extreme operating conditions of gas turbine combustion chambers is proposed. The proposal is based on the observation that, within probable experimental uncertainty, the limited soot oxidation measurements correlate with the more extensive measurements of the surface oxidation rates of macroscopic sized samples of pyrographite. The soot oxidation rates thus determined for the conditions of a typical gas turbine combustion chamber are considerably lower than previous estimates which were based on simple extrapolations of the flame data.
\end{abstract}

\section{INTRODUCTION}

Although in gas turbine engines the formation of soot in the combustion chamber has a negligible effect on the specific fuel consumption, its 
presence is undesirable since it contributes to radiant heat transfer to the combustion chamber walls and to the level of particulate emissions in the exhaust. In response to recent public concern over the smoke trails from jet aircraft, engine manufacturers have made design modifications which generally have resulted in leaner and better mixed primary combustion zones (Faitani 1968). There has been a consequent large decrease in exhaust visibility (Sawyer 1970), but apparently with only fractional reductions in the actual quantity of particulates emitted and an increase in the formation of nitrogen oxides. Direct measurements suggest that much of the carbon formed in the primary zone may be burned up during its passage through the secondary zone where cooling air is added (Toone 1968), and the posstbilfty arises that, with proper addition of secondary air, the particles may be completely consumed. In order to investigate this possibility further, it is necessary to have a fairly accurate estimate of the oxidation properties of soot at the appropriate combustion chamber operating conditions.

Measurements of the oxidation rate of soot particles in the product gases of laboratory flames have been made by Lee, Thring, and Beér, (1962), Tesner and Tsibulevsky (1967) and Fenimore and Jones (1967). It is generally agreed that soot particles in flames are so small (typically $0.05 \mu$ diameter) that the oxidation rate is not limited by diffusion of gases to and from the surface of the particle, but by the rate of the heterogeneous chemical reaction at the surface; this is usually represented by $\omega$ and expressed in the units:gms carbon $\cdot \mathrm{cm}^{-2} \cdot \mathrm{sec}^{-1}$. 
Based on their observations made using six different soot diffusion flames, Lee et al. correlated their measurements of the soot oxidation rate by the empirical formula,

$$
\omega=1.085 \times 10^{4} \frac{\mathrm{P}_{0}}{\mathrm{~T}^{1 / 2}} \exp (-39,300 / \mathrm{RT})
$$

where the partial pressure of oxygen, $\mathrm{P}_{0_{2}}$, was varied between 0.04 and 0.1 atm and temperature, $\mathrm{T}$, between 1300 and $1700^{\circ} \mathrm{K}$.

Tesner and Tsibulevsky also suggest a first-order dependence of $w$ on $\mathrm{P}_{\mathrm{O}_{2}}$ and an activation energy close to $40 \mathrm{kcal} / \mathrm{mole}$. Although the $\mathrm{P}_{\mathrm{O}_{2}}$ values are not stated explicitly, they appear to be on the order of $0.01 \mathrm{~atm}$. The rates were observed to be in good agreement with those of Lee et a1. and if extrapolated to about 0.2 atm. using a first-order dependence on $\mathrm{P}_{\mathrm{O}_{2}}$,-also agreed with those of Walls and Strickland-Constable (1964) which were obtained from an experiment on the oxidation of GEC 430 pyrographite in a high-speed oxygen jet.

Fenimore and Jones examined the oxidation of soot in a premixed flame with oxygen, hydrogen, and carbon dioxide and found that, for oxygen partial pressures in the range $10^{-4}$ to $0.3 \mathrm{~atm}$, and temperatures between 1530 and $1890^{\circ} \mathrm{K}$, the rate is only weakly dependent on oxygen concentration. They correlated their measurements by assuming that the hydroxyl radical was the primary oxidant, effective in about 10 per cent of its collisions with the surface in removing a carbon atom. Fenimore and Jones also argued that this $\mathrm{OH}$ oxidation mechanism could account for about 60 per cent of the rate observed by Lee et al., implying that both $\mathrm{OH}$ and $\mathrm{O}_{2}$ were probably important. 


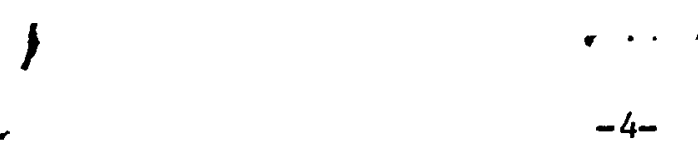

Unfortunately, for our present purposes, all these measurements on soot oxidation were made at pressures and temperatures well below those encountered in gas turbine engines (Heywood et a1., 1970). Extrapolation is uncertain, especially in view of the apparent disagreement on the order of the reaction with respect to the oxygen concentration. However, the apparent similarity in the graphitic-like structures of small soot particles and large specimens of pyrographite prompted us to make a detailed comparison between the few soot oxidation rate measurements and the more extensive measurements of pyrographite oxidation. If good correspondence was then observed, the pyrographite oxidation rate measurements could provide us with a sounder basis for extrapolating the soot oxidation rates to the higher pressures and temperatures appropriate to gas turbine combustion chambers. In the following section, Section II, we shall make this comparison, and in Section III we shall utilize a formula correlating the pyrographite oxidation rate measurements to estimate the burn-up times of small soot particles in a typical gas turbine combustion chamber.

II. COMPARISON OF SOOT AND PYROGRAPHITE OXIDATION RATES: X-ray studies of soot particles (Palmer and Cullis 1965) indicate that they have a turbostratic structure; 1.e., they are made up of graphite-like platelets each containing on the order of a hundred or so carbon atoms orientated so that their basal plane is approximately tangent to the surface, but stacked randomly on top of one another. A similar structure is found in pyrographites which have been formed from the high temperature deposition of simple hydrocarbon molecules such as 
$\mathrm{C}_{2} \mathrm{H}_{4}$ on formers (Bokros 1969). In attempting to compare the oxidation rates of these two types of carbon, we will restrict ourselves to those cases in which care was taken to eliminate the influence of gas-phase diffusion on the surface oxidation and in which the measured recession of the surface due to oxidation was observed to occur in the c-direction, i.e., normal to the basal planes. There is considerable evidence to show that high temperature oxidation rates with molecular oxygen are anisotropic with respect to the $\mathrm{c-}$ and $\mathrm{m}$-directions by factors of 10 or more (Thomas 1965, Rosner and Allendorf 1968).

Figure 1 is an Arrhenius type plot of $\log _{10} \omega$ versus $104 / \mathrm{T}$, and contains the results of several experiments as well as the full curves which were calculated for various values of the oxygen partial pressure, $\mathrm{P}_{0_{2}}$, from the semi-empirical formula given by Nagle and Strickland-Constable (1962) which they claimed to correlate the measured rates of pyrographite oxidation. The notation $W, S-C$ refers to data obtained by Walls and Strickland-Constable $(1964)$ at $\mathrm{P}_{\mathrm{O}_{2}}=0.21$ atm using $\mathrm{GEC} 430$ pyrographite in a high-speed oxygen jet. Earlier data from the same group using H.T.M. pyrographite (Nagle and Strickland-Constable 1962) scatters in the same region but is not plotted here in order to avoid confusion. The similarity in the oxidation rates of these two pyrographites led these workers to believe that the oxidation mechanism may not be too dependent on the method of preparation of the pyrographite. The notation $\mathrm{R} \& \mathrm{~A}$ identifies the results of Rosner and Allendorf (1968) obtained using pyrographite which was formed in situ in their experimental apparatus by the decomposition of ethane at $1920^{\circ} \mathrm{K}$ on a tungsten filament. Although 
their results were originally presented as efficiencies of removal of carbon atoms for each oxygen molecule collision with the surface at a stated pressure, we have converted to the units of $\omega$ using kinetic theory. The $10^{-3}$ atm and $10^{-4}$ atm points were obtained from Figure 3 of their paper. Early measurements by Strickland-Constable, quoted in Nagle and Strickland-Constable (1962), using carbonized filaments at very low pressures, $\mathrm{P}_{\mathrm{O}_{2}}=2.5 \times 10^{-5}$ atm, are identified in Figure 1 as $\mathrm{S}-\mathrm{C}$. Finally, the point, $T$, represents an estimate made by Thomas (1965) at $\mathrm{P}_{0_{2}}=1.3 \times 10^{-2}$ atm for the oxidation of graphite in the c-direction from microscope measurements.

Nagle and Strickland-Constable's (1962) correlation formula is based on the concept that a fraction, $x$, of the total sites on the carbon surface at which oxidation takes place are of an active type, $A$, the remainder being less active, type $B$. A steady-state analysis of their surface oxidation mechanism yields the result:

$$
\frac{\omega}{12}=\left(\frac{k_{A} P_{0_{2}}}{1+k_{z} P_{0_{2}}}\right) x+k_{B} P_{0_{2}}(1-x)
$$

where the first and second terms refer to removal of carbon atoms from $A$ and $B$ sites, respectively,

$$
\chi=\left\{1+k_{T} /\left(k_{B} p_{0}\right)\right\}^{-1}
$$

and the empirical rate coefficlents are given as:

$$
\begin{array}{ll}
\mathrm{k}_{\mathrm{A}}=20 \exp (-30,000 / \mathrm{RT}) & \mathrm{gm} \text {-atom } \cdot \mathrm{cm}^{-2} \cdot \mathrm{sec}^{-1} \cdot \mathrm{atm}^{-1} \\
\mathrm{k}_{\mathrm{B}}=4.46 \times 10^{-3} \exp (-15,200 / \mathrm{RT}) & \text { gm-atom } \cdot \mathrm{cm}^{-2} \cdot \mathrm{sec}^{-1} \cdot \mathrm{atm}^{-1}
\end{array}
$$




$$
\begin{array}{ll}
k_{T}=1.51 \times 10^{-5} \exp (-97,000 / \mathrm{RT}) & \text { gm-atom } \cdot \mathrm{cm}^{-2} \cdot \mathrm{sec}^{-1} \\
k_{z}=21.3 \exp (4100 / \mathrm{RT}) & \mathrm{atm}^{-1}
\end{array}
$$

In the above we have used the same notation as Nagle and StricklandConstable in which the activation energies for the various kinetic processes are given in cal.mole $\mathrm{e}^{-1}$ and have been chosen so that they give a best fit to the pyrographite oxidation measurements. Indeed, It can be seen from Figure 1 that the formula does correlate these measurements quite well, particularly at the higher pressure and temperatures which are of interest to us here. The primary disagreement is with the low pressure measurements of Rosner and Allendorf, but in this region the experimental evidence is contradictory.

The formula demonstrates a fractional order dependence of $w$ on $\mathrm{P}_{\mathrm{O}_{2}}$, and for each value of $\mathrm{P}_{\mathrm{O}_{2}}$, wexhibits a maximum at a particular temperature. The first effect arises because the degree of coverage of the A sites by a surface oxide increases with increasing oxygen pressure in accordance with the Langmuir isotherm, and the second effect arises because the proportion of A sites to B sites begins to decrease beyond a certain temperature. This proportion, given by $X$, is determined at any temperature by the rate of $\mathrm{B}-\mathrm{site}$ oxidation and the rate of an annealing process which converts A sites to B sites; the physical nature of each site is obscure.

Turning now to the measurements of soot oxidation, we have represented in Figure 1 the rates deduced by Lee et al. (1962) by the shaded area marked LTB. When we bear in mind the probable experimental uncertainty associated with the flame measurements, it appears to us that there 
is acceptable agreement with the Nagle and Strickland-Constable formula both in terms of the absolute value of $\omega$ and the dependence on temperature. It is apparent from the pyrographite oxidation results that a very accurate estimate of $\omega$ would have to be made to distinguish a true pressure dependence. Thus, we feel that Lee, Thring, and Beér's first-order pressure dependence would really have to be established over a much vider range of pressure to contradict the pyrographite results.

Fenimore and Jones' measurements, identified by FJ, obtained in both lean flames and for dry soot oxidation also show good absolute agreement with the pyrographite results, and the weak pressure dependence they observed over a seven-fold change in $\mathrm{P}_{\mathrm{O}_{2}}$ is accounted for. We suggest that the rates they measured in the rich flames may be due to traces of oxygen greater than their equilibrium estimates, but still too small to measure. We therefore do not believe it is necessary at this point to postulate an oxidation mechanism involving the hydroxyl radical. In fact, Rosner and Allendorf (1970) have recently observed that ofl removed a carbon atom from 1sotropic graphite less frequently than once every hundred collisions with the surface; this is well below the 10 per cent efficiency that Fenimore and Jones postulated. Since there is no obvious reason to suppose that carbon atoms would be removed more easily from soot particles than from isotropic graphite, we would expect that the contribution OH makes to the oxidation rate is small.

We have not plotted Tesner and Tsibulevsky's soot oxidation results because of the uncertainty in the oxygen partial pressure. However, these authors did comment that if their results were extrapolated on the 
basis of a first-order dependence on the oxygen partial pressure, their rate constant did agree with that of Nagle and Strickland-Constable at $\mathrm{P}_{\mathrm{O}_{2}}=0.2 \mathrm{~atm}$. There is disagreement at lower oxygen pressures due to the differing oxygen partial pressure dependences each found. Nevertheless, the Tesner and Tsibulevsky data reveal an activation energy at lower temperatures which agrees closely with the other work, and which, as the temperature increases, explicitly shows a decrease in accordance with the pyrographite results.

Summarizing, the measurements of soot oxidation rates which have been made in flames appear to be in reasonable agreement with the pyrographite oxidation measurements and are thus adequately correlated by the semi-empirical formula given by Nagle and Strickland-Constable. Considering the quality and scope of the experimental information available, a readjustment of the Nagle and Strickland-Constable parameters does not seem warranted at present. Clearly, however, there is a need for measurements on soot oxidation rates in the practically important temperature range above $2000^{\circ} \mathrm{K}$, where it may be expected that the rate attains a maximum value, and where its dependence on the oxygen pressure would be more easily measured than at lower temperatures.

\section{APPLICATION}

The time required to completely burn a spherical soot particle is dependent on the particle radius and the surface reaction rate. For a given rate, $\omega$, there is a steady rate of change of the radius given by the expression: 


$$
\frac{d r}{d t}=-\frac{10^{4} \omega}{\rho_{s}}=-5 \times 10^{3} \omega \quad\left(\text { micron } \sec ^{-1}\right)
$$

if the density of soot, $\rho_{s}$, is assumed to be $2 \mathrm{gm} \mathrm{cm}^{-3}$.

The Nagle and Strickland-Constable formula and the simplified plug-flow model of the mixing and combustion processes in the gas turbine engine developed by Heywood, Fay and Linden (1970) will be used to estimate the reduction in a particle's radius during its passage through the combustion chamber. From Figure 2 of Linden and Heywood (1971) we obtain the axial stoichiometry variation as a function of flow time. We adopt their initial conditions of primary zone equivalence ratio, $\phi=1.2$ and compressor air at 15 atm and $700^{\circ} \mathrm{K}$. The local temperature and oxygen partial pressure are assumed to be that for the equilibrlum products of an adiabatic reaction of $\mathrm{C}_{n} \mathrm{H}_{2 n}$ fuel with the compressor afr and are given as a function of $\phi$ in Figure 2, taken from Linden (1970).

The surface recession rate, $\mathrm{dr} / \mathrm{dt}$, (micron/sec) which we calculate is given as a function of $\phi$ in Figure 3. The maximum rate is estimated to be about $17 \mathrm{micron} / \mathrm{sec}$, or about $1 / 6$ of that calculated by Heywood et al. (1970) using the Lee, Thring, and Beér correlation formula. The maximum occurs at a slightly leaner mixture in the present case; 1.e., $\phi=0.75$ as compared to 0.80 . For equivalence ratios in the ranges $\phi<0.5$ and $\phi>1.0$, the rate is less than $2 \mathrm{micron} / \mathrm{sec}$. Integrating the curve shown in Figure 3 through the secondary zone and assuming a total transit time of $5 \mathrm{msec}$ yields a surface recession of 0.021 micron, of which 80 per cent takes place between 10 and 30 per cent of the 
distance of travel in this zone. We therefore estimate that particles whose infial diameters are about 0.04 micron or less should be totally consumed; this is a typical size for soot particles sampled from flames (Palmer and Cullis 1965). Remembering the cubic dependence of volume on diameter, those particles which remain should be only a fraction of their original mass. In this situation we would expect agglomeration of the spherical soot particles in the region where they are formed to be probably important in determining the visibility of the smoke trail. We would also expect that the quantity of soot emitted could be reduced by prolonging the residence time of the soot particles at conditions where $\phi \sim 0.75$.

We note that the maximum rate of nitric oxide formation occurs close to $\phi=1.0$ (Heywood, et al., 1970) so that prolonging the residence time of soot particles at $\phi \sim 0.75$ should not cause a significant increase in the emissions of nitric oxide. 


\section{REFERENCES}

Bokros, J. C. (1969) "Deposition, Structure, and Properties of Pyrolytic Carbon," in Chemistry and Physics of Carbon (P. L. Walker, Jr., ed.) 5. $1-118$.

Faitani, J. J. (1968) "Smoke Reduction in Jet Engines through Burner Design," S.A.E. Transactions 77, 1080-1090.

Fenimore, C. P. and Jones, G. W. (1967) "Oxidation of Soot by Hydroxy 1 Radicals," J. Phys. Chem. 71, 593-597.

Heywood, J. B., Fay, J. A., and Linden, L. H. (1970) "Jet Aircraft Air Pollution Production and Lispersion," AIMA 8th Nerospace Sciences Heeting, Paper No. 70-115.

Lee, K. B., Thring, K. W., and Beér, J. M. (1962) "On the Rate of Combustion of Soot in a Laminar Soot Flame," Combustion and Flame 6 , $137-145$.

Linden, L. H. (1970) "The Production of Solld Carbon in Gas Turbine Combustors," M. S. Thesis, Dept, of Mechanical Engineering, M.I.T. Linden, L. H. and Heywood, J. B. (1971) "Smoke Emission from Jet Engines," o Combustion Science and Technology 2, 401-411.

Nagle, J. and Strickland-Constable, R. F. (1962) "Oxidation of Carbon between 1000-2000 $\mathrm{C}, "$ Proc. of the Fifth Carbon Conference 1, 154164.

Palmer, H. B. and Cullis, C. R. (1965) "The Formation of Carbon from Gases," Chemistry and Physics of Carbon (P. L. Walker, Jr. ed.) 1, 265-325. 
Rosner, D. E. and Allendorf, H. D. (1968) "Comparative Studies of the Attack of Pyrolytic and Isotropic Graphite by Atomic and Molecular Oxygen at High Temperatures," AIAA Journal 6, 650-654. Rosner, D. E. and Allendorf, H. D. (1970) "Kinetics of the Attack of Refractory Materials by Dissociated Gases," In Heterogeneous Kinetics at Elevated Temperatures, Proceedings of the International Conference in Metallurgy and Materials Science, Univ. of Pennsylvania, 1969. (G. R. Belton and W. L. Worre11, eds.) Plenum Press, 231-251. Sawyer, R. F. (1970) "Reducing Jet Pollution Before It Becomes Serious," Astronautics and Aeronautics 8, 62-67.

Tesner, P. A. and Tsibulevsky, A. M. (1967) "Gasification of Dispersed Carbon in Hydrocarbon Diffusion Flames, III. Flames of AcetyleneHydrogen and Acetylene-Water Vapor Mixtures," Combustion, Explosion and Shock Waves 3, 1963-1967. (1969) (Translation from Fizika Gorenya i Vzryva 3, 261-267).

Thomas, J. M. (1965) "Microscopic Studies of Graphite Oxidation," Chemistry and Physics of Carbon (P. L. Walker. Jr. ed.) 1, 121-202. Toone, B. (1968) "A Review of Aero Engine Smoke Emission,"Cranfield International Symposium Series 10, Combustion in Advanced Gas Turbine Systems (I. E. Smith ed.) Pergamon Press.

Walls, J. R. and Strickland-Constable, R. F. (1964) "Oxidation of Carbon Between $1000-2400^{\circ} \mathrm{C}, "$ Carbon 1, 333-338. 


\section{FIGURE CAPTIONS}

Figure 1 - Arrhenius plot displaying $\log _{10} \omega$ versus $10^{4} / \mathrm{T}$ for carbon oxidation. The points refer to experimental data for the oxidation rates of soot particles and pyrographite samples. The letter symbols are explained in the text, and the numbers in parentheses refer to the appropriate partial pressure of oxygen in atmospheres. The solid curves were calculated from the semi-empirical formula of Nagle and StricklandConstable (1962) at the pressure of oxygen indicated in atmospheres on each curve.

Figure 2 - Adiabatic flame temperature, $T\left({ }^{\circ} \mathrm{K}\right)$ and partial pressure of oxygen, $\mathrm{P}_{0_{2}}$ (atm), for equilibrium combustion products of $\mathrm{C}_{\mathrm{n}} \mathrm{H}_{2 \mathrm{n}}$ and $700^{\circ} \mathrm{K}$ air at 15 atm. as a function of equivalence ratio, $\phi$.

Figure 3 - Estimated rate of surface recession of a soot particle, $\mathrm{dr} / \mathrm{dt}$, as a function of equivalence ratio, $\phi$, for the temperature and oxygen pressure variation given in Figure 2. 


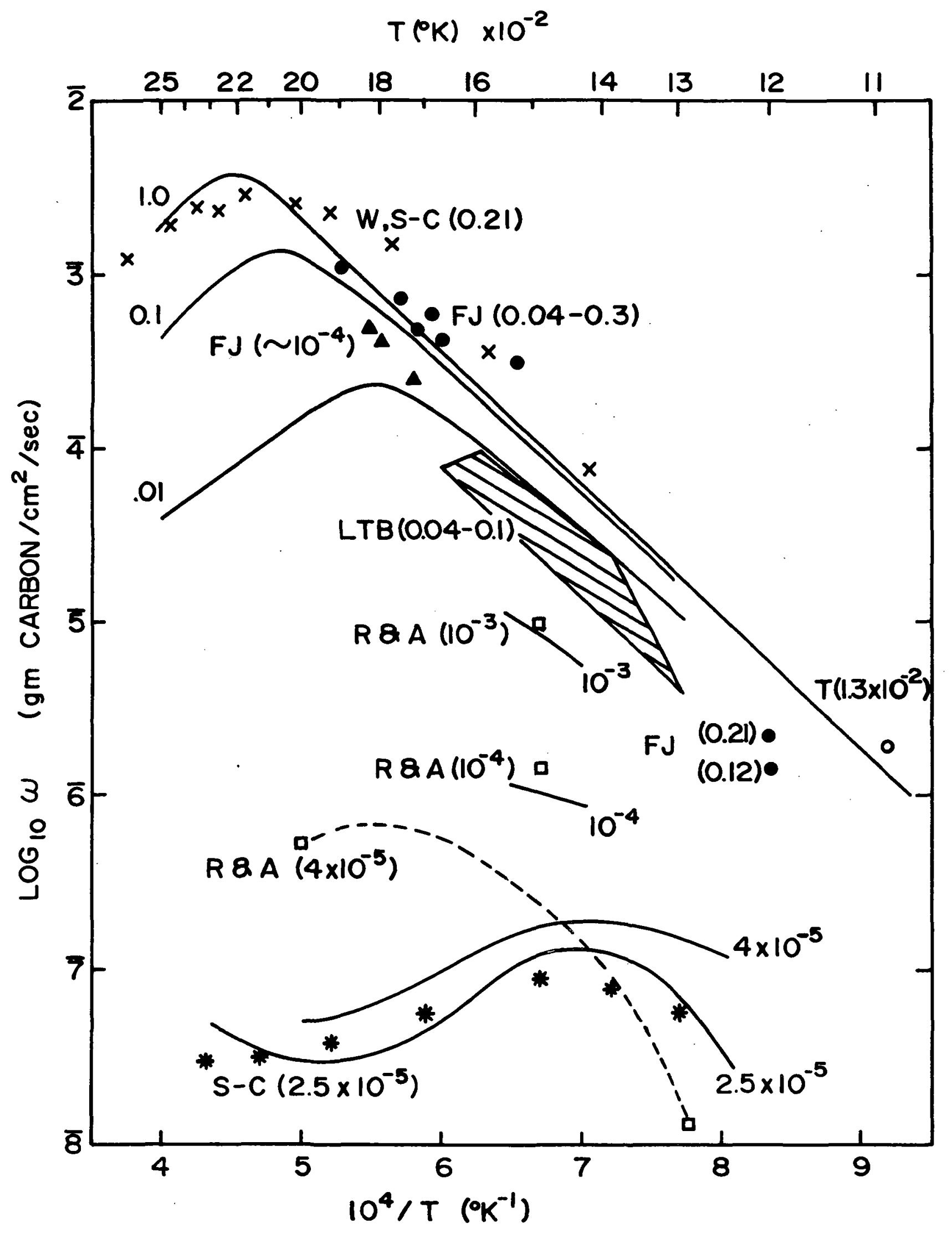

FIGURE I 


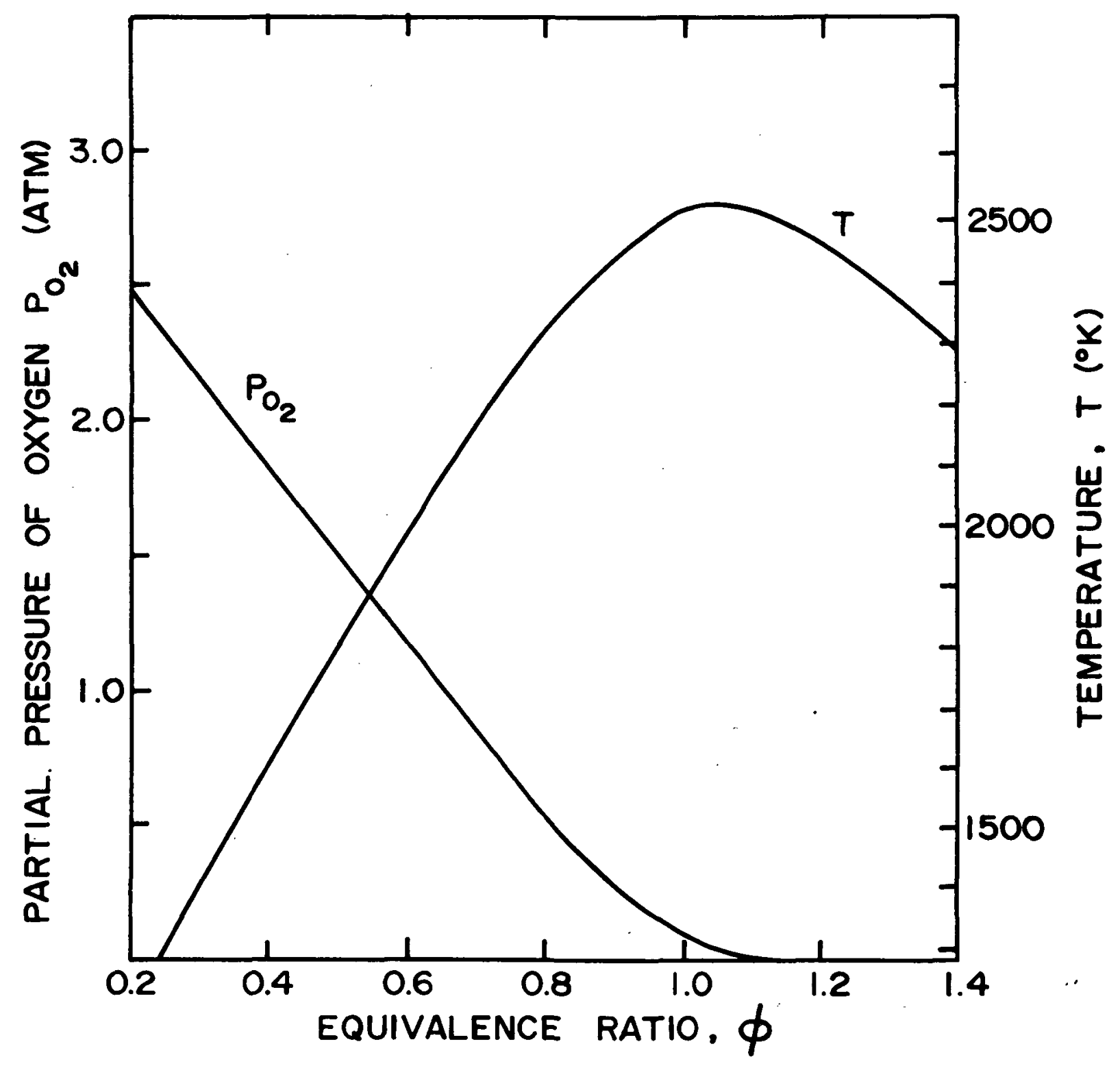

FIGURE 2 


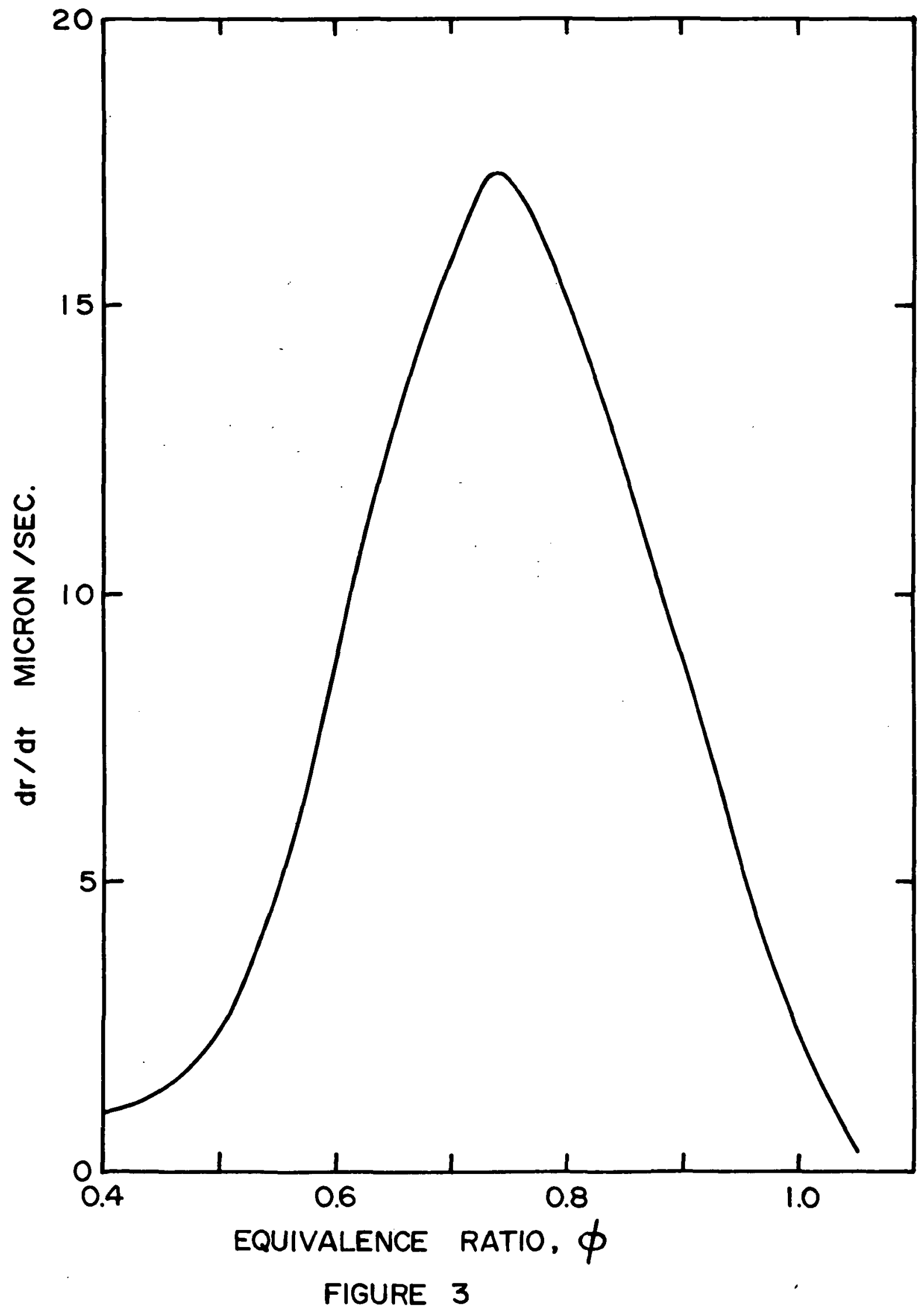

